\title{
INCLUSION THROUGH DIGITAL ARTS: CREATING A COMMUNITY OF PRACTICE
}

\author{
Ana Barata ${ }^{1}$, Paula Escudeiro ${ }^{2}$, Valérie Duarte ${ }^{3}$ and Jadir Lino ${ }^{4}$ \\ ISEP; GILT \\ Rua Dr. António Bernardino de Almeida, 4314249-015 Porto, Portugal
}

\begin{abstract}
To communicate is the deepest will of every human being since their very first minute of existence, as communication is what makes human beings really feel part of a whole. One of the most transversal, barrier-dropper, and universal ways of communicating is creating art. Having that assumption in mind, this paper introduces a proposal for combining technology and arts production using an online educational Community of Practice aimed at encouraging communication and collaboration between blind/low vision individuals and deaf/hearing impaired individuals having the creation of digital artworks using a technologically developed collaborative environment. To provide a framework for this challenge, this study provides a review of concepts and examples related to the art practices from an inclusive point of view, to inclusive design, and to the essential features of reliable Communities of Practice. Furthermore, the proposal for developing a collaborative environment for creating digital artworks, combining the best practices and features of the analyzed examples, targeting at the blind and deaf communities is described as well as the evaluation model - the Quantitative Evaluation Framework - to be used to assess this creative learning and communication environment.
\end{abstract}

\section{KEYWORDS}

Collaboration, Community of Practice, Digital Arts, Inclusive Design, QEF

\section{INTRODUCTION}

The technological development, and the improvement of digital systems have revolutionized the way human beings interact not only with each other but also with the world around, they interfere with people's work habits, with the education environments, and have opened the path for a wide set of communication possibilities in myriad contexts. Being able to communicate is what makes human beings feel, and really be, part of a whole (Gomes 2009). Interacting, understanding, sharing, feeling and being integrated are unquestionable conditions for belonging to a community, regardless of abilities, disabilities, origin or condition, and one of the most fascinating, transversal, barrier-dropper, and universal means of communication is creating art.

In this paper we propose to combine the already long and close relationship between the arts and technology (Paul 2003), (Greene 2004), (Chung 2006), (Barata 2014) with the learning and challenging potential of online Communities of Practice (CoP), introducing a proposal for developing an inclusive collaborative learning and creative environment aimed at allowing blind and deaf individuals to produce digital artworks together. This project derives, on the one hand, from the authors' experience in working with assistive technology and interaction projects (P. Escudeiro et al. 2013; B. P. Marques et al. 2017; P. M. Escudeiro et al. 2018), and on the other hand from the strong interest the authors have in contributing for diversifying and for the further development of various means and environments that may propel inclusive learning, working to tear apart barriers and to enrich human-human interaction. This way, the authors wish to put the technological innovation at the service of inclusion.

\footnotetext{
${ }^{1}$ abt@isep.ipp.pt

2 pmo@isep.ipp.pt

3 1171493@isep.ipp.pt

4 jadirlino@gmail.com
} 
To better address our proposal, and to clearly framework it, this paper starts by reviewing the field of digital arts, focusing especially on art practices, experiences and productions that can be embraced as inclusive and/or produced by blind or deaf artists, once the deaf and the blind are our primary target audiences. Then, an overview of inclusive design concepts, purposes and practices is presented to scaffold the essential background that is being studied to build an appropriate learning and creative environment. Afterwards, the demands and features of CoPs are detailed, followed by our concept proposal of an inclusive collaborative environment, which is going to be assessed with the Quantitative Evaluation Framework (P. Escudeiro and Bidarra 2006), and tested with deaf and blind people.

\section{DIGITAL ARTS TOWARDS INCLUSION: PERSPECTIVES}

The arts have an already long and close relationship with technology, dating from the $20^{\text {th }}$ century's 60 s the first references to scientific and technological work within the arts field (Greene 2004), (Barata 2014). Nam June Paike, David Medalla, Roy Ascott are only few of the first artists who started exploring the potential of the by-then new media and tools, opening the path for what became known as the Experiments in Art and Technology Group, which gathered artists and engineers working together on the same creative projects (Barata 2014, 1)

That was when "inclusion" from an inter-and-multidisciplinary perspective started within the arts. Moreover, the social and educational role played by the arts became more accessible and recurrent following the requirements set by the advances in computing, and by the publics' participation (Popper 2007, 1975). Art, in particular digital art, started being present at homes, cybercafes and any public or private space with internet access, mobile, wireless, or local (Wands 2006, 8). Accessing as well as experiencing and producing art became easier and more flexible, authors started adopting interactive and collective strategies, embracing a wide variety of spaces, perspectives and formats (Barata 2014, 10-38). Therefore, referring to an artwork as "digital" implies that it was created using digital tools, software, or any technological means, therefore it "can be described as an electronic series of zeros and ones" (Lieser and Morbey 2009). These technological means are used either to explore or to create artworks, sometimes they are the artwork itself like the Pinokio Lamp, created with Arduino, and OpenCV (Zhou, Ben-Dror, and Doggett 2012; Ben-Dror 2012). Motion, immersion, smell, and sound "communicate simultaneously on four levels: sensory, emotional, mental and spiritual. It is this multiple synchronicity of body, mind and intellect that helps to define our complex reactions to art, as well as to the everyday world," states Wands (2006). People experience through their senses, that is what makes human-beings unique. Digital artworks appeal to all the senses, individually or simultaneously, thus they cannot be perceived as objects but as concepts, information, perspectives that reflect an author's or a collective of authors' views on specific issues. There is no "object" (Chierico 2016), but an experience, the way the audience interacts, feels, reacts to, i.e., how the audience experiences the digital artwork is the artwork itself. The dominant senses depend on each individual's characteristics. Vision, movement, vibration, tactile experiences are essential senses for a deaf person. Movement, tactile experiences, smell, touch, taste, sound are essential senses for a blind person, and essential for experiencing contemporary art.

In Pittsburgh, the Andy Warhol Museum launched a guide to Warhol's artworks aimed at enabling the blind to have a direct experience of contacting with the works, hence making both the author's life and work accessible to people who cannot see them, which includes not only an audio guide called Out Loud but also tactile reproductions of a number of Warhol's works (The Andy Warhol Museum 2019).

Art Beyond Sight: A Resource Guide to Art, Creativity and Impairment, Art education for the Blind, published by the American Foundation for the Blind, already in 2002, was one of the first books to analyze the arts education perspective for blind/low vision people, focusing on how blind/low vision people create art, and on how they experience, interact with it and enjoy it. Blind people who are given the opportunity to experience art are able to understand it, including form, depth, and perspective (Axel 2003).

It is our belief that the polyform possibilities, immersive experiences and countless interconnections made available by digital technology, make the digital the best field to explore and integrate in an environment intended to widen communication, engagement, creativity and inclusion of blind and of deaf people through collaborative artistic performance. Next section handles inclusive design concepts and examples, focusing on the essential assets for creating an inclusive, user-friendly web environment, essential to our aims. 


\section{UNDERSTANDING INCLUSIVE DESIGN}

Before embracing Inclusive Design, it is essential to understand what inclusion and exclusion mean. Going back to its Latin origin, "inclusion" means to shut in while "exclusion" means to shut out. Considering inclusivity as a circle holding inside all that should be included, exclusivity, as its antonym, keeps everything out of that circle. Hence, people usually tend to promote inclusivity as they believe in the possibility of being in a large circle in which almost everything fits. Known as "Design for All" in Europe, and as "Universal Design" in the USA, the history of Inclusive Design goes back to the beginning of the European social ideals materialized after the World War II, which include healthcare and housing for everyone (John Clarkson and Coleman 2015). In early approaches, its focus was in designing for disabled and elderly people. In 2000, the UK Government defined Inclusive Design as products, services and environments that include the needs of the widest number of consumers (Brand and Brooker 2015). However, as part of recent international trends towards inclusion, Inclusive Design goes beyond targeting at older and disabled people to also focus on so far excluded groups, including the blind and the deaf.

Most recently, Microsoft expanded the concept of Inclusive Design by defining it as a methodology, born out of digital environments, which enables and draws on the full range of human diversity. Most importantly, this means including and learning from people with myriad perspectives. Microsoft also presents two distinctions. The first refers to universal design as strong at describing the qualities of a final design, specifically as to the nature of physical objects. The second, originally from Treviranus, points out that universal design is one-size-fits-all while inclusive design is one-size-fits-one (Microsoft 2018).

Accessibility criteria are the foundation of integrity for any inclusive solution (Holmes 2018), in which inclusive design has to be considered. The resulting designs, though for people with permanent disabilities, are often beneficial for a larger number of people. For example, automatic doors were created for the visually impaired community and for people with mobility issues, but they also benefit people with situational limitations such as an arm injury, or a parent holding an infant. Inclusive design does not imply always designing products to address the entire population's needs. Instead, it implies devising an appropriate design response to diversity in the population. The Persona Spectrum used by Microsoft to understand related mismatches and motivations across a spectrum of permanent, temporary, and situational scenarios is a useful easy-to-use tool that helps foster empathy, providing a possible scalable audience scenario in inclusive design thinking. Table 1 exemplifies that Persona Spectrum we are applying to develop the collaborative creative learning platform.

Table 1. Persona Spectrum providing permanent, temporary and situational targeted scenarios

\begin{tabular}{llll}
\hline Scenarios & Permanent & Temporary & Situational \\
\hline Vision & Blind & Cataract & Distraction \\
& Color blindness & Looking at a bright light & When driving a car \\
& Farsightedness & Eye injury & \\
& Partially visually impaired & & \\
\hline Hearing & Deaf & Middle ear infection & Bartender \\
& Hearing impaired & Being exposed to a loud & Music performer \\
& & sound/noise & \\
& Excess of earwax & \\
& &
\end{tabular}

After recognizing and accepting that different people have different needs for accessibility, it is easier to allow people to choose how they want to interact with an experience. The pyramid model of diversity (Figure 1) can be used to show how inclusive design aims at extending the target audience to include those with some kind of disability, while accepting that specific solutions may be required to satisfy the needs of those at the top of the pyramid (Engineering Design Centre 2017). 


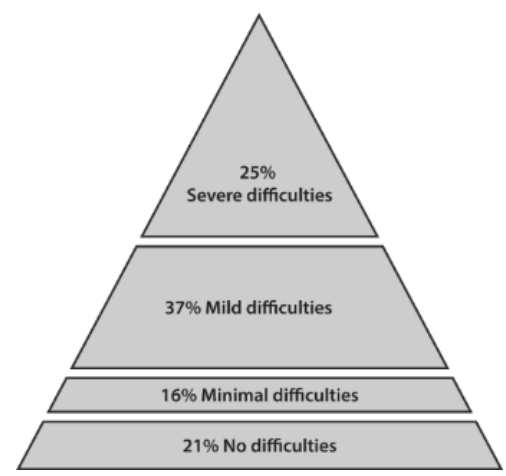

Figure 1. Pyramid Model of Diversity (Engineering Design Centre 2017)

On the other hand, co-design is a collaborative design process. It is often considered an inclusive method deployed to gather data by recognizing the participant as a partner not only during the data gathering phase, but also during implementation, delivery, and validation (Steen, et. Al., 2011). Collaborative sessions or workshops are the main platform where participants cooperate with researchers. These sessions differ based on both context and needs; nevertheless, three basic stages are present in almost all participatory design research: Initial Exploratory Work; Discovery process, Prototyping. The last stage involves using a variety of techniques for interactively shaping artifacts. These techniques can include, among others, mock-ups and paper prototyping. The best practice in inclusive design is to create the objects or environments with the participation of people with disabilities, or who have experienced any accessibility issue.

In the early 19th century, Pellegrino Turri, a skilled mechanic from Italy, built the first working model of a typing machine and invented carbon paper, which served as the machine's ink, inspired by his affection for the Contessa Fantoni, a childhood friend who was blind. Being blind, the countess was unable to write letters in private and autonomously, so Turri decided to create a mechanical solution to allow her to communicate with the world (Dictionary.com 2019). The result was a typing machine that associated a letter with a specific key that could be tapped to imprint on carbon paper, making writing accessible to blind people. Centuries later, modern keyboards and mobile devices are in use. The touch-sensitive imaging technology grew out of Wayne Westerman's UD doctoral thesis. He developed the revolutionary computer interface technology with John Elias, who was at the time a UD professor in the College of Engineering. Wayne had tendonitis which motivated him to tinker with different types of input technology. After some testing, he noticed that his hands had more endurance with zero-force input like optical buttons and capacitive touch pads than with force-actuating keys and buttons. Later, his company, the FingerWorks, created the first prototype of a touchpad for each hand to replace the keyboard, which was popular among people with hand disabilities and with temporary hand injuries. His work was so relevant that culminating in Apple buying the rights to the technology which was used for developing the first gesture-controlled multi-touch interface for the iPhone (Roberts 2014). These are only two examples that people tend to think in numerous creative ways to do what they enjoy or value, and work to develop the means they need. Designing environments to be inclusive impacts positively on individuals, on businesses, on society. Inclusive environments promote independence, empower the population and foster accessibility to content. These benefits lead exclusion and friction to be put aside and enable positive emotional contexts to blossom. This is also our motivation to develop a collaborative learning and creative environment that enables blind and deaf people to produce digital artworks.

Once personal computers and currently mobile devices as well have enormously enhanced the autonomy and the communication abilities of people with diverse disabilities, those are the devices where our environment will be accessed from. We aim at an adequate user interface design which will have high impact on the users' social lives. Approaching the creation of this collaborative environment user interface, focusing on a collaborative process during all the phases of its design, implies including blind and deaf people (our target primary users) in a user centered design methodology. It is not about creating "one thing for all people", it is about creating diverse ways for people to participate with a sense of belonging. In our proposal, inclusive design expands with the audience, i.e., our development model for the environment interface embraces the users' feedback, evolves considering their perspectives along with our views. Our User Centered Inclusive Design Model represented in Figure 2 considers our target audience (user-centered), our purpose (to be inclusive), the way we act and perceive development (cooperatively), and our output (design). 


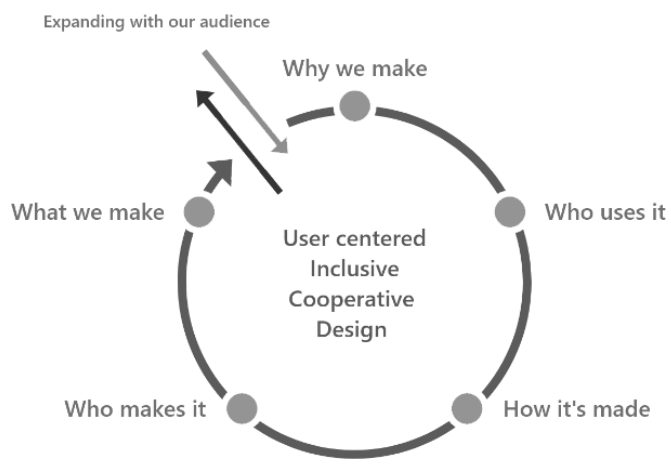

Figure 2. Representation of our model: Inclusive design expanding with the audience

\section{ENGAGEMENT TOWARDS INCLUSION IN A COP}

Etienne Wenger and Jean Lave theorized that the learning process does not rest in the individual but in a social process, given the culture and communities where the individual interacts and learns. The concept of Communities of Practice $(\mathrm{CoP})$ directly emerges from that theory, as it can be described as a group of individuals that gather together in communities, around a common topic or shared concern, passion or something they want to learn in any given domain of our society. However, not all communities are CoPs and some CoPs may not be intentionally focused on the learning process. For instance, a neighborhood might be called a community but it is not usually a CoP; however, a group of nurses that have lunch together every day and who might dive into sharing information about their individual practices during the job, thus expanding their base knowledge in a daily basis, may be considered a non-intentional CoP.

A CoP has therefore three crucial characteristics: the Domain, the Community and the Practice (Farnsworth, Kleanthous, and Wenger-Trayner 2016), whereas the Domain is a group of people who are committed to each other and, consequently, share competences that distinguish their members from other people. The Community refers to the members' engagement in joint activities and discussions over subjects of their interest. Nevertheless, having the same job does not structure a CoP unless there is an effort to interact and learn from each other. The practice is what makes any community a real CoP, a community with a domain is not a CoP unless practitioners of their field develop a repertoire of experiences, stories, and ways to address recurring problems. According to Wenger, it is a common mistake to try to engage all members of the community in an equal level of participation (Wenger, McDermott, and Snyder 2002). Given the different levels of interest, the members can be divided into three groups: the main group, the active group, and the periphery group. The main group is often the one guiding the CoP for being more engaged in the activities, it represents $10 \%$ to $15 \%$ of the members. The active group, around $15 \%$ to $20 \%$ of the members, are people who attend meetings, and take part in the forum discussions but are not as engaged as the main group. Most members lay in the peripheral body, $65 \%$ to $75 \%$, those are the ones that rarely take part in the activities but watch the group's interactivities. However, these members are not as passive as they might seem, they have their own insights of the discussions, and practice putting those to good use (Wenger, McDermott, and Snyder 2002).

Community-based art is a creative expression that emerges from communities of people working together to improve their individual and collective circumstances (Schwarzman, 2006). Following this statement, the aim of the Inclusive Digital Arts Practice Community conceptualized in this paper is to be an online inclusive environment fostering communication, collaboration, education, learning, integrative knowledge, and creativity, in which the virtual learning environment plays a major role. Focusing on the blind and deaf people, this $\mathrm{CoP}$ integrates both in a single environment. Taking into account their particular capacities, we are creating a multimedia environment that aims to translate the perspective and understanding of one community environment to the other in a feasible way, through a multi-modal interactive interface where it is possible to create digital artworks in both sound and image formats, allowing for blind and deaf to communicate during the process, devising in such a way a piece of digital art perceived by both. For this it is essential to consider the sound-colour correspondence, following the studies performed by (Ward, Huckstep, and Tsakanikos 2006; Bischin 2018). 


\section{QEF - THE ASSESSMENT METHODOLOGY}

A simple question for any educational social network or CoP should be: "Can this educational environment really do what it is supposed to?" This simple question may lead to many beguiling features. It requires the evaluator to recognize his/her own view of the way users learn, to relate that view with the learning objectives and to determine how and whether those objectives are carried out in the online and self-standing platform. This is even more challenging and demanding when an inclusive social network is being considered.

The application of QEF, which has already been successfully applied in controlling the quality of several products with very positive results (P. Escudeiro 2007), (B. Marques et al. 2018), throughout the development life cycle of an inclusive social network highlights the flaws present in the version at the time of evaluation, allowing the development team to focus on those flaws, and guiding them through the improvement process to achieve the desirable requirements. Moderating the development of an inclusive social network with QEF assures the quality of the results (P. Escudeiro 2015). QEF enables evaluating the inclusive educational social network quality in a three-dimensional space, each of which aggregates a set of factors. The quality of a given system is, hence, defined in our three-dimensional Cartesian quality space and measured, in percentage, relatively to a hypothetically ideal system represented in our quality space by the coordinates $(1,1,1)$. The coordinates of a given system in our quality space may be obtained through the application of one of several aggregation forms. These coordinates will be computed as the average of the factors contributing to it. The average is simple and gives the same relevance to all factors.

The quality space is defined by the content expert. In our present proposal this is the expert in digital arts. Regarding the inclusive social network, the definition of the Cartesian quality space will be settled on the following dimensions: Pedagogical, Ergonomic, and Technical - each of these dimensions aggregates a set of factors for which it is important to determine our proposed system's performance degree. In this case, a factor is an element that will represent the performance of the digital content in the system, according to predetermined criteria (P. Escudeiro 2015). For our quality scenario, two factors were added in the Pedagogical dimension: The Learning Factor and the Evaluation Factor. The Ergonomics dimension is the aggregation of three factors: Usability, Video/Audio, and Text. The Technical domain reflects the digital content quality regarding the functional factors. This dimension includes adaptability and content management. Through them we can measure to what extend the scenario and the system content are effective - whether they are focused on and able to present different instructional design theories and different learning environments in a common platform, i.e., if they interconnect fluently. However, in the scope of our present proposal, we want to evaluate a very specific network based on inclusion. We wish to promote the quality of an inclusive social network that involves digital arts collaborative production. Having this in mind, we need to create a new specific quality space for the inclusive social network. The dimensions or aspects of our Cartesian quality space are the Technical Domain, the Ergonomic Domain and the Pedagogical Domain.

The Technical Dimension reflects the characteristics of the digital content regarding operational aspects. This dimension adds the following factors: adaptability and content management, as included in Table 2.

The Ergonomic Dimension is related to the scientific knowledge, the design and development of tools that guarantee the overall performance of a given educational environment and can be used easily and safely, (Wisner, Fialho \& apud Santos 1995), i.e., the aspects that directly affect the work that must be done in their technical, ergonomic and social aspects: Usability, Video/Audio, and Text, as considered in Table 3.

The Pedagogical Dimension is based on the teaching/learning process supported by the learning criteria. Learning is determined by various factors involving the interrelationship between individuals. Therefore, we believe evaluation to be a tool of a teaching/learning environment that leads us to technological procedures supported by educational issues (Bloom, 1983, Bloom 1964): cognitive, affective, psychomotor (Table 4).

Table 2. Technical Domain Characteristics

\begin{tabular}{ll}
\hline Id & Technical Domain \\
\hline F1 & Adaptability \\
\hline F2 & Content management \\
\hline
\end{tabular}

Table 3. Ergonomic Domain Characteristics

\begin{tabular}{ll}
\hline Id & Ergonomic Domain \\
\hline F3 & Usability \\
\hline F4 & Video/Audio \\
\hline F5 & Text \\
\hline
\end{tabular}


Table 4. Pedagogical Domain Characteristics

\begin{tabular}{ll}
\hline Id & \multicolumn{1}{c}{ Pedagogical Domain } \\
\hline F6 & Learning \\
\hline F7 & Evaluation \\
\hline
\end{tabular}

There are considerable differences in the learning criteria between the Ergonomic dimension and the Pedagogical dimension. The Ergonomic dimension refers to the way of learning how to operate the system (usability) while the Pedagogical dimension refers to the way of learning with a system (learning). Both domains, however, human and computer, are closely connected, enabling the cooperative and collaborative development of digital artworks, straightening human-to-human communication within the inclusive social network or CoP. This way, it is possible to develop an evaluation system addressing fundamental assessment properties for evaluating the quality of digital learning content.

\section{CONCLUSION}

This paper introduced a proposal for developing an inclusive collaborative learning and creative educational environment focused on enabling blind and deaf individuals to create digital artworks together. This project contributes to foster inclusive learning, and human-to-human interaction by means of technological innovation. A short review of digital arts concepts, especially highlighting practices involving deaf and blind communities was included. The overview on inclusive and cooperative design enabled to conceive the inclusive design model we are following to design the collaborative environment considering our target audience, our purpose, the way we act and perceive development, and our output. The evaluation methodology ensures the environment's consistence, robustness and effectiveness. The direct collaboration of associations for the deaf as well as associations for the blind are collaborating in the concept of this transversal inclusive environment for fostering communication, engagement, learning, creativity and interaction between blind and deaf people.

\section{ACKNOWLEDGEMENT}

The authors thank to the R\&D group GILT, and to the Portuguese National Funding Agency for Science, Research and Technology (FCT) for the funding of the ACE-Assistive Communication for Education Project, in which scope this research is being developed.

\section{REFERENCES}

Axel, Elisabeth Salzhauer. 2003. Art Beyond Sight: A ResourceGuide to Art, Creativity, and Visual Impairment. Edited by Elisabeth Salzhauer Axel and Nina Sobol Levent. 1st ed. New York: American Foundation for the Blind Press. https://books.google.pt/books?id=B4ioCFic7m0C\&printsec=frontcover\&hl=pt-

PT\&source=gbs_ge_summary_r\&cad $=0 \# v=$ onepage \&q $\& \mathrm{f}=$ false.

Barata, Ana. 2014. 'Despertar Consciências: Activismos e Artes Digitais'. Lisboa: FCSH-Universidade Nova de Lisboa. http://hdl.handle.net/10362/13086.

Ben-Dror, Adam. 2012. 'Pinokio'. indexhibit. 2012. http://ben-dror.com/pinokio/.

Bischin, Maria-Roxana. 2018. 'Music and the Sound: A Philosophy of Perception'. Brolly, Journal of Social Sciences 1 (2): 83-91. https://www.journals.lapub.co.uk/index.php/Brolly/article/view/65.

Brand, Johan, and Jamie Brooker. 2015. 'Inclusive Design - a People Centered Strategy for Innovation'. 2015. http://www.inclusivedesign.no/ict/kahoot-article172-261.html.

Chierico, Alessio (interviewer). 2016. 'Media Art and Art Market: An Interview with Wolf Lieser • Digicult | Digital Art, Design and Culture'. 2016. http://digicult.it/news/media-art-art-market-interview-wolf-lieser/.

Chung, Sheng-Kuan. 2006. 'Digital Storytelling in Integrated Arts Education'. The International Journal of Arts Education 4 (1): 33-50. http://ed.arte.gov.tw/uploadfile/Periodical/1320_arts_education41_033050.pdf.

Dictionary.com, LLC. 2019. 'Typewriters Were Originally Created to Help the Blind'. Dictionary.com, LLC. 2019. https://www.dictionary.com/e/is-this-goodbye-to-the-typewriter-learn-the-love-story-that-helped-create-thetypewriter/. 
Engineering Design Centre. 2017. 'Inclusive Design Toolkit: What Is Inclusive Design?' Cambridge University. 2017. http://www.inclusivedesigntoolkit.com/whatis/whatis.html.

Escudeiro, Paula. 2007. 'Avaliação de Conteúdos Digitais [Evaluation of Digital Contents]'. In E-Conteúdos Para E-Formadores [E-Contents for E-Trainers]. Braga: TecMinho/Gabinete de Formação Contínua 2015. 'Unidade Curricular-CAMUL'. P.Porto.

Escudeiro, Paula, and José Bidarra. 2006. 'X-TEC: Techno-Didactical Extension for Instruction / Learning Based on Computer - A New Development Model for Educational Software'. In WEBIST 2006, Proceedings of the Second International Conference on Web Information Systems and Technologies: Society, e-Business and e-Government $/$ e-Learning. Setúbal.

Escudeiro, Paula, Nuno Escudeiro, Rosa Reis, Maciel Barbosa, José Bidarra, Ana Bela Baltazar, and Bruno Gouveia. 2013. 'Virtual Sign Translator'. International Conference on Computer, Networks and Communication Engineering (ICCNCE 2013), no. Iccnce: 290-92. https://doi.org/10.2991/iccnce.2013.72.

Escudeiro, Paula Maria, Tiago Oliveira, Nuno Escudeiro, and Fernando Maciel Barbosa. 2018. 'ACE Assisted Communication for Education: Architecture to Support Blind \& Deaf Communication'. In 2018 IEEE Global Engineering Education Conference (EDUCON), 1015-23. Tenerife: IEEE. https://doi.org/10.1109/EDUCON.2018.8363341.

Farnsworth, Valerie, Irene Kleanthous, and Etienne Wenger-Trayner. 2016. 'Communities of Practice as a Social Theory of Learning: A Conversation with Etienne Wenger'. British Journal of Educational Studies 64 (2): 139-60. https://doi.org/10.1080/00071005.2015.1133799.

Gomes, Maria do Céu. 2009. 'O Ensino Do Português Num Contexto de Educação Bilingue'. Revista Diversidades, no. 25 : $10-14$.

Greene, Rachel. 2004. 'Internet Art'. Art Book 6: 224. http://www.amazon.com/dp/0500203768.

Holmes, Kat. 2018. 'The No. 1 Thing You're Getting Wrong about Inclusive Design'. 2018. https://www.fastcompany.com/90243282/the-no-1-thing-youre-getting-wrong-about-inclusive-design.

John Clarkson, P., and Roger Coleman. 2015. 'History of Inclusive Design in the UK'. Applied Ergonomics 46 (PB): 235-47. https://doi.org/10.1016/j.apergo.2013.03.002.

Lieser, Wolf, and Helena (translated by) Morbey. 2009. Arte Digital. Königswinter: Tandem Verlag GmbH h.f.ullmann.

Marques, Bertil, Ana Barata, Piedade Carvalho, Ana Silva, Patrícia Queirós, and Paula Escudeiro. 2018. 'Applying the Quantitative Evaluation Framework Model for Ensuring the MOOC Quality'. In MCCSIS 2018 - Multi Conference on Computer Science and Information Systems; Proceedings of the International Conferences on e-Learning 2018. Vol. 2018-July.

Marques, Bertil P., Piedade Carvalo, Paula Escudeiro, Ana Barata, Ana Silva, and Sandra Queiros. 2017. 'Post Graduations in Technologies and Computing Applied to Education: From F2F Classes to Multimedia Online Open Courses.' In International Association for Development of the Information Society, edited by Miguel Baptista Nunes and Maggie MacPherson, 55-62. Lisbon: International Association for the Development of the Information Society. e-mail: secretariat@iadis.org; Web site: http://www.iadisportal.org. https://eric.ed.gov/?id=ED579389.

Microsoft. 2018. 'Inclusive Design'. 2018. https://www.microsoft.com/design/inclusive/.

Paul, Christiane. 2003. Digital Art. London: Thames \& Hudson.

Popper, Frank. 1975. Art, Action, and Participation. New York: New York University Press 2007. From Technological to Virtual Art. Cambridge, London: The MIT Press.

Roberts, Karen B. 2014. 'Tech Pioneers UD Inventors of Touch Imaging Interface Technology Inducted as NAI Fellows'. Edited by University of Delaware. UDaily. University of Delaware. 2014. http://www1.udel.edu/udaily/2014/may/naifellows-052714.html.

Schwarzman, Mat, and Community Arts Criticism. 2006. 'Community-Based Art for Social Change', 9-10.

The Andy Warhol Museum. 2019. 'Out Loud + Tactile Art Reproductions'. The Andy Warhol Museum. The Andy Warhol Museum. 2019. https://www.warhol.org/accessibility-accommodations/.

Wands, Bruce. 2006. Art of the Digital Age. Thames \& Hudson.

Ward, Jamie, Brett Huckstep, and Elias Tsakanikos. 2006. 'Sound-Colour Synaesthesia: To What Extent Does It Use Cross-Modal Mechanisms Common to Us All?’ Cortex 42 (2): 264-80. https://doi.org/10.1016/S0010-9452(08)703526.

Wenger, Ethiene, Richard Arnold McDermott, and William Snyder. 2002. Cultivating Communities of Practice: A Guide to Managing Knowledge. Boston, Massachussetts: Harvard Business School Practice.

Zhou, Shanshan, Adam Ben-Dror, and Joss Doggett. 2012. Pinokio Lamp. New Zealand: Victorian Wellington University. https://vimeo.com/52366512. 